\title{
Can Health Trainers Make a Difference With Difficult-to-Engage Clients? A Multisite Case Study
}

\author{
Dianne Kerlin
}

A political attempt in the United Kingdom to address health inequalities in the past decade has been the government's initiative to employ local health trainers (HTs) or health trainer champions (HTCs) to support disadvantaged individuals with aspects of their health-related behaviors. HT/HTCs provide healthrelated information and support to individuals with healthy eating, physical activity, and smoking cessation. They undertake community engagement and direct individuals to relevant health services. They differ in that HTs are trained to provide health interventions to individuals or groups and to make referrals to specialist health care services when necessary. This article provides an evaluation of HT/HTCs interventions across three sites, including one prison, one probation service (three teams), and one mental health center. An evaluation framework combining process and outcome measures was employed that used mixed methods to capture data relating to the implementation of the service, including the context of the HT/HTCs interventions, the reactions of their clients, and the outcomes reported. It was found that HT/HTCs interventions were more effective in the prison and mental health center compared with the probation site largely as a result of contextual factors.

Keywords: health trainer; health promotion; mental health; offender health

Health Promotion Practice

Month XXXX Vol. XX , No. (X) 1-9

DOI: $10.1177 / 1524839915572802$

(c) 2015 Society for Public Health Education

\section{INTRODUCTION}

Health trainers'-(HTs') and health trainer champions' (HTCs') contribution to health education/promotion in the United Kingdom was introduced in Choosing Health (Department of Health [DH], 2004) and the government's strategy Healthy Lives: Healthy People (DH, 2010), as a method by which people in disadvantaged communities could be supported to achieve behavioral change for health and well-being.

HTs and HTCs provide health-related information and support to individuals with healthy eating, physical activity, and smoking cessation (White, Woodward, \& South, 2013). They undertake community engagement and direct individuals to relevant health services. They differ in that HTs are trained to provide health interventions to individuals or groups and to make referrals to specialist health care services when necessary (Michie et al., 2008).

A pilot scheme, in 2005 saw HT/HTCs recruited in 12 early adopter sites in some of the most deprived areas of the United Kingdom. Since 2005 their recruitment has expanded and they have been introduced into prison health care (Brooker \& Sirdifield, 2007) and probation services (Dooris, McArt, Hurley, \& Baybutt, 2013). Bailey and Kerlin (2012) evaluate a\# HT introduced in a mental health center, which forms part of the wider evaluation reported in this article.

${ }^{1}$ Nottingham Trent University, Nottingham, UK

${ }^{2} B B C$, Manchester, UK

Authors' Note: The project was funded with support from Durham and Darlington Primary Care Trust who commissioned the evaluation of the Health Trainer/Champion Service. Address correspondence to Di Bailey, School of Social Sciences, Nottingham Trent University, Chaucer 3211, Burton Street, Nottingham, NG1 4BU,UK; e-mail: di.bailey@ntu.ac.uk. 


\section{LITERATURE REVIEW}

Trayers and Lawlor (2007) suggest that addressing health inequality in the United Kingdom is complex and that approaches to tackling it tend to ignore the circumstances in which the individual lives, focusing solely on individual behavior by offering support and intervention to effect lifestyle change. This individualistic approach is reflected in White et al-'s (2013) synthesis of eight HT service evaluations in socially deprived areas of the United Kingdom.

An evaluation of the HT pilot scheme in Bradford (South, ood, \& Loek, 2007a, 2007b) found that HTs' effectiveness hinged on the "peer support" they were able to offer as members of the same local communities. HTs' success in engagement depended on them being flexible and taking small steps with clients and demonstrating core competencies such as listening, supporting, empathizing, and empowering clients, giving clients the confidence to self-refer to other services. Similarly, in Derbyshire, HT/HTCs were found to be flexible, empathetic, and providing plenty of time for service users (Denness, Keeton, \& Fearn, 2011). Subsequent evaluations have also demonstrated a positive picture, with clients reporting good overall satisfaction with the service they received. Clients valued having direct contact with their HT, and the knowledge and information they were provided with (Morgan, 2011; White \& Kinsella, 2011).

Brooker and Sirdifield (2007) evaluated the impact of HT services in one of the offender health adopter sites, where offenders were recruited as HTs in a prison. The assessment showed largely positive findings for both the offenders trained as HTs and their clients. HTs were found to have acquired new skills as a result of their training around healthy living and behavior change. In terms of clients, approximately half admitted to no previous engagement with prison health care prior to their visit to the HT; yet $75 \%$ indicated they would return for a second HT appointment.

HT contributions to offender health have also demonstrated potential for reducing reoffending as well as increasing healthy behaviors (Baybutt \& Dooris, 2011). Sirdifield (2006) suggests that this is because offenders may value the peer to peer interaction with an HT who is also incarcerated (Sirdifield, 2006). However Dooris et al. (2013) conclude that the number of clients in probation services who complete a personal development plan (PDP) are significantly fewer in number than clients in community-based HT services in the United Kingdom.

The contribution of HTs in mental health services reveals a more mixed response. A mental health center was included as a study site for the evaluation reported in this article and the effects of this HT's intervention with service users with severe and enduring mental health needs have been reported previously (Bailey \& Kerlin, 2012). In other studies (Preston \& Romero, 2011; White \& Kinsella, 2011), HT's interventions were not specific to individuals with mental health issues although findings suggested improvements to individuals' confidence and well-being generally. Denness et al. (2011) were unable to recruit an HT to work specifically with individuals with housing and mental health issues and speculate that this may have been because of the perceived difficulties of working with this client group. In Bradford, HTs were reportedly daunted by the nature of clients with unexpected mental health and social problems (South et al., 2007a, 2007b). HTs in Nottingham reported similar struggles, and as a result Morgan (2011) and Mason, Knuckey, Perkins, and Bellis (2011) suggest that mental health awareness should be included in training for HTs to prepare them for working with this client group.

Much of the academic literature on HT/HTCs services has emerged after 2010 (White et al., 2013), thus predating this study, which began in 2009 to explore the role of HTs and HTCs across three sites with groups considered "difficult" to engage in relation to health care interventions.

Employing a case study approach (Stake, 1995; Yin, 2009), data were collected in three sites, using a multilevel evaluation framework developed by Bailey (2002, 2007 ) that combined process and outcome evaluations. The sites were a Category A prison, a probation service (three teams), and a mental health center. Although HTs were based in probation services and in the mental health center, while HTCs worked within the prison, the only difference in the way HT/HTCs delivered the service was that the HT in the mental health center offered group sessions to clients. The HTs undertook the City and Guilds Health Trainer Qualification, and the HTCs received the Royal Society of Public Health Level 2 Award with an additional 1 day of mental health awareness training. By using the same evaluation framework in all three sites, it became possible to compare the HT/HTCs' contributions with different client groups and in different settings.

\section{METHODOLOGY}

The evaluation framework combined levels of evaluation originally proposed by Warr, Bird, and Rackham (1970), Kirkpatrick (1994), and Barr, Freeth, Hammick, Koppel, and Reeves (2000) developed and refined through previous research, by Bailey and Littlechild 
(2001) and Bailey $(2002,2007)$. Mixed methods allowed data to be gathered across four levels, importantly including the organizational context in which the HT/ HTCs were operating as this level of evaluation had been missing in most of the other studies (White et al., 2013). The evaluation framework also considered the effectiveness of the HT/HTC inputs, the reactions of their clients, and any outcomes relating to changes in their own and their clients' behavior.

Data collected included quantitative and qualitative findings as shown in Table 1.

Data relating to the role of stakeholders in the implementation of HT/HTC services were also collected as stakeholders were integral to the setting up and delivery of the service in all three sites. Stakeholders included the following:

- Four HTs (three women and one man) and six HTCs (all men) who were trained specifically to deliver the service

- Two commissioners who were senior managers in primary care health trusts and had secured funding for the HT/HTC service as well as commissioned the evaluation

- One coordinator (nurse trained) who supported the HTCs in the prison

- Seven prison staff

- Nine health service managers who recruited the HTs in probation services and in the mental health center, acted as their line managers and reviewed their work in relation to health targets

\section{Data Analysis}

Minutes from stakeholder meetings were subject to documentary analysis to assess the strengths, limitations, opportunities, and threats of each context (adapted from DuBrin, 2013; Humphrey, 2005). Comments from interviews and focus groups were analyzed using a grounded theory approach (Strauss \& Corbin, 1998). Comments were read and reread, then grouped into themes and subthemes, and cross-checked by both researchers to ensure the validity and reliability of categories across the three sites and the different levels of evaluation. Where direct quotes from stakeholder interviews are included to illustrate key themes, these have been anonymized and coded as (I1) and so on.

\section{FINDINGS}

\section{Context Evaluation}

A common theme across all sites was the need for commissioners and managers to proactively support the introduction of HT/HTCs. Steering groups were set up in all sites to lead and oversee the implementation of the HT service. In the prison, the steering group developed the infrastructure, implemented the training program for HTCs, and brought in the coordinator who was responsible for their ongoing support and mentoring. In the probation services, implementation was overseen by a strategic group whose membership included commissioners and an operational group including team managers. The strategic group recruited the HTs, while the operational group supported them to embed their interventions within the probation services and report back on targets set/targets met to the strategic group. In the mental health center, the steering group included the center managers, and the HT was responsible for developing the role in the center.

Theme A: Networking and Communication. Reflecting similar evaluations (White et al., 2013), networking and communication emerged in all three sites as pivotal to the successful implementation of HT/HTC services. Each site developed a specific plan for raising awareness of the HT/HTC role. In the prison, this involved HTCs wearing T-shirts advertising their HTC status, their photographs were displayed on wing notice boards, and information on how to contact them was circulated at prisoner induction and in an article in the prison newsletter.

In the probation services, efforts concentrated on collecting knowledge about how other HT/HTCs worked across the United Kingdom. Managers placed importance on understanding the implementation process in the event of commissioners deciding to continue to fund the service. Emphasis was placed on ensuring that the value of the role to clients was clear. A coordinator was appointed partway through the project to liaise between the three teams involved and support HTs to increase client uptake.

At the mental health center, the HT was already known as a volunteer. When he became an HT, he began raising awareness of the role and generating interest among clients already attending the center. His approach was inclusive, encouraging everybody to attend his sessions.

In the mental health center, effective networking with referring agencies became particularly important. The HT established 13 partnerships with services, including specialist mental health teams, physical activity/exercise groups, and individuals qualified to provide specialist activities. These networks proved critical to an inclusive and flexible HT service in the center in line with clients' needs. 
TABLE 1

Data Collection Sources and Method

\begin{tabular}{|c|c|c|c|c|c|}
\hline Case Study Site & $\begin{array}{l}\text { HTs or } \\
\text { HTCs }\end{array}$ & Context Evaluation & Input Evaluation & $\begin{array}{l}\text { Reaction } \\
\text { Evaluation }\end{array}$ & Output Evaluation \\
\hline \multirow[t]{2}{*}{1 Prison } & \multirow[t]{2}{*}{6 HTCs } & $\begin{array}{l}9 \text { sets of steering group meeting } \\
\text { minutes (August 2008-May } \\
\text { 2010) }\end{array}$ & \multirow[t]{2}{*}{$\begin{array}{l}\text { Individual session } \\
\text { logs ( } 389 \text { contact } \\
\text { sessions in total) }\end{array}$} & $\begin{array}{l}\text { Focus group } \\
\text { with the } 6 \\
\text { HTCs at the } \\
\text { completion of } \\
\text { training }\end{array}$ & $\begin{array}{l}\text { STAR attitudinal } \\
\text { tool completed by } \\
\text { HTCs at beginning } \\
\left(\mathrm{T}_{1}\right) \text { and end of } \\
\text { training }\left(\mathrm{T}_{2}\right) \text { to } \\
\text { assess attitudes in } \\
\text { relation to health } \\
\text { and health-related } \\
\text { issues }\end{array}$ \\
\hline & & $\begin{array}{l}10 \text { interviews with } 3 \\
\text { stakeholders (members of the } \\
\text { project steering group), } 7 \\
\text { prison employees including } \\
\text { staff working on the wings, } \\
\text { health care and PE personnel }\end{array}$ & & $\begin{array}{l}\text { Evaluation form } \\
\text { completed by } \\
12 \text { clients }\end{array}$ & $\begin{array}{l}\text { Evaluation form } \\
\text { completed by } 12 \\
\text { clients }\end{array}$ \\
\hline \multirow[t]{2}{*}{$\begin{array}{l}3 \text { Probation } \\
\text { teams }\end{array}$} & \multirow[t]{2}{*}{$3 \mathrm{HTs}$} & $\begin{array}{l}8 \text { sets of strategic group } \\
\text { meeting minutes (August } \\
\text { 2009-July 2010) }\end{array}$ & $\begin{array}{l}\text { Interview with } 1 \\
\text { HT }\end{array}$ & \multirow[t]{2}{*}{$\begin{array}{l}\text { Evaluation form } \\
\text { completed by } 6 \\
\text { clients }\end{array}$} & $\begin{array}{l}\text { DCRS }^{\text {a }} \text { data for } 39 \\
\text { clients }\end{array}$ \\
\hline & & Interviews with 8 stakeholders & $\begin{array}{l}\text { Referral figures for } \\
\text { the service (April } \\
\text { 2010-December } \\
\text { 2010) }\end{array}$ & & $\begin{array}{l}\text { Evaluation form } \\
\text { completed by } 6 \\
\text { clients }\end{array}$ \\
\hline \multirow[t]{4}{*}{$\begin{array}{l}1 \text { Mental health } \\
\text { center }\end{array}$} & \multirow[t]{4}{*}{$1 \mathrm{HT}$} & \multirow[t]{4}{*}{ Interviews with 3 stakeholders } & $\begin{array}{l}\text { Interview with the } \\
\text { HT }\end{array}$ & $\begin{array}{l}\text { Evaluation form } \\
\text { completed by } 9 \\
\text { clients }\end{array}$ & $\begin{array}{l}\text { DCRS data for } 72 \\
\text { clients }\end{array}$ \\
\hline & & & \multirow{3}{*}{$\begin{array}{l}\text { Breakdown and } \\
\text { average } \\
\text { attendance of } \\
\text { group work }\end{array}$} & \multirow[t]{3}{*}{$\begin{array}{l}\text { Focus group } \\
\text { with } 3 \text { clients } \\
\text { and the HT }\end{array}$} & $\begin{array}{l}2 \text { progress reports } \\
\text { produced by the } \\
\text { HT }\end{array}$ \\
\hline & & & & & $\begin{array}{l}2 \text { case study reports } \\
\text { prepared by the } \\
\text { HT }\end{array}$ \\
\hline & & & & & $\begin{array}{l}\text { Evaluation form } \\
\text { completed by } 9 \\
\text { clients }\end{array}$ \\
\hline
\end{tabular}

NOTE: HT = health trainer; HTC = health trainer champion.

a. DCRS (Data Collection Reporting System) was part of the commissioners' requirements, which recorded information about clients, including demographics, client goal/targets, and progress information.

Theme B: Environment and Clientele. Demographic information was obtained from the Data Collection Reporting System (DCRS) in the probation services $(n=$ 39) and mental health center $(n=72)$.

There was a higher number of females $(n=32)$ than males $(n=7)$ in probation services, with 20 being between 36 and 55 years old. This gender split contrasts with Dooris et al. (2013). The number of clients older than 36 years in probation services was higher than the national average for HT clients at the time of data collection (DCRS, 2010).

In the mental health center, the opposite gender ratio was identified (males, $n=50$; females, $n=22$ ). The majority of clients were between 26 and 45 years of age 


\begin{tabular}{|l|l|}
\hline Level of Evaluation & Number of themes \\
\hline \multirow{2}{*}{ Context } & A Networking and communication \\
\cline { 2 - 2 } & B Environment and clientele \\
\hline \multirow{2}{*}{ Input } & A Health Trainer attributes and values \\
\cline { 2 - 3 } & B Client issues and goals \\
\cline { 2 - 2 } Outcome/Reaction & A Health Trainer attitude change \\
\cline { 2 - 2 } & B Self-reported impact on client's behaviour \\
\hline
\end{tabular}

FIGURE 1 Emerging Themes

TABLE 2

Attendance Figures

\begin{tabular}{lcccc}
\hline & Number of HT/ & & & \\
Site & HTCs & Appointments & Attendance (\%) & Reason Did Not Attend \\
\hline Prison & 6 HTCs & 389 & 100 & NA \\
Probation services & 3 HTs & 297 & 63 (187 attended) & $\begin{array}{c}35 \%(105) \text { did not attend; } 2 \% \\
\text { (5) cancelled/rescheduled }\end{array}$ \\
\hline
\end{tabular}

NOTE: HT = health trainer; HTC = health trainer champion.

$(62 \%)$, reflecting a higher number of attendees in this age-group than the national average (DCRS, 2010). Clients opted to self-refer from within the center or were referred by an external organization.

In the prison, all the HTC clients were male, and all were older than 18 years, reflecting the demographic of the custodial setting.

Table 2 compares the appointment and attendance figures for the prison and probation services. Because the HT was available to assist clients at any time within the mental health center, no appointment data were collected.

Perhaps unsurprising in a contained, custodial setting, the HTCs had a higher number of appointments and $100 \%$ of clients attended within the period of data collection. Probation services saw a higher number of appointments (99/HT in probation services compared with 65/HTC in the prison), but in the probation services a higher number of clients did not attend. This poor attendance rate was explored in the interviews with the HTs and stakeholders, who said that is was the chaotic lifestyle of offenders that led to their nonattendance.

The nature of these people is that if they miss an appointment, they tend to think that they will not get another chance, so they just tend to dismiss it. (I1)

\section{Input Evaluation}

Theme A: Health Trainer Attributes and Values. A key attribute for HT/HTCs was trust. Within the prison, HTCs were subject to internal security checks and had to be considered trustworthy by staff before they were appointed to the role. Suitable candidates were recommended by the prison officers on the wings.

Security checks were made on all men expressing an interest. This was to identify if they were suitable to be trusted to work in a one to one situation with fellow prisoners. (I14)

In the mental health center building, trust became important as some clients were initially put off by the HT's attempts to record personal details or information on relating to their PDPs. Stakeholders said that clients could be put off by the paperwork because "People can be in delusions, afraid and/or paranoid" (I3). The HT reported that he had found that the best way to alleviate these concerns was to gather progress data during activities, in informal chats with clients.

Sometimes I get the information in group sessions, for example, I may get communication from a client whilst cycling next to them. That way they 
sometimes do not realize they are even talking about their health, and that's how I find it can be better to interact. (I4)

Flexibility and commitment emerged as other key attributes for the HT in the mental health center. The HT offered clients a range of activities, at different times, and set up groups based on clients' suggestions. Commitment was vital for reinforcing clients' trust. For example, on one occasion, when a bike ride was not possible due to adverse weather conditions, the HT arranged a group walk instead of cancelling the activity, which avoided clients' disappointment.

Other key attributes for HT/HTCs identified in the prison and mental health center were HT/HTCs' helpfulness, informative approach, facilitative style, approachable manner, and understanding nature.

Theme B: Client Issues and Goals. Across all sites, fitness, exercise, physical activity, and diet emerged as the main issues that clients wanted help with.

In the prison, 155 of the 389 appointments were concerned with fitness/exercise (78 contacts) or healthy eating (77 contacts). The remaining contacts related to information about the HTC role/prison issues, general health and accessing health services or help with form filling, smoking cessation, and mental health.

In the mental health center, 66 out of 72 clients set their PDP goal to increase physical activity ( 47 male and 19 female) and 4 to eat more healthily ( 2 male and 2 female). In probation services, clients identified a primary goal of diet (35 out of 39) and exercise (1 client).

In relation to specific fitness and exercise help, clients required assistance with creating and maintaining exercise plans (prison and mental health center), assistance with joining the gym (prison and mental health center), and help with incorporating physical activity into lifestyle (all sites). Fitness and physical activity were most common goals in prison and in the mental health center (approximately $92 \%$ of clients raised this issue and set a subsequent goal).

In terms of healthy eating, clients required diet information, healthy eating food sheets, and specific dietary information (all sites) and food and cooking assistance (prison and mental health center). Healthy eating and/or diet issues were most common in prison and probation services (approximately 90\% of clients in probation services requiring help with this issue).

In terms of goal setting, 15 out of 39 clients in probation services set specific PDP goals with the HT, with 10 clients setting their main goal to lose weight, 3 to have a healthier diet, and 2 to increase their selfesteem. In the mental health center, 66 of the 72 clients set goals in relation to increasing physical activity and 4 out of 72 clients set a goal of eating more healthily.

\section{Outcome/Reaction Evaluation}

Theme A: Health Trainer Attitude Change. An attitude change to health and lifestyle was reported by HT/ HTCs in the prison and mental health center in terms of improved fitness levels, enhanced knowledge of health, and increased appetite for additional learning.

I've never been in a job that is so active. It has definitely helped my own fitness. . . . I have to be very aware that I should still be leading by example. (I4)

In the prison, HTCs' attitude change was assessed using the Outcomes Star ${ }^{\mathrm{TM}}$ (Triangle Consulting Social Enterprise, 2009), a simple-to-administer tool designed to show change in attitudes diagrammatically on a 10-point scale. This was administered at the beginning of training sessions and after completion of the full training course. The Outcomes Star ${ }^{\mathrm{TM}}$ assessed eight areas: alcohol use, use of time, physical health, emotional and mental health, drug misuse, offending, money, and family relationships.

Scoring suggested an improvement for all HTCs in six out of the eight attitudinal areas except alcohol and family relations. HTCs said their attitudes to alcohol use stayed positive and constant because they were unable to obtain alcohol in custody. Relationships with family members were reported more negatively after the training than before it because several of the HTCs said the training had helped them understand that their criminal behavior prior to prison had been influenced by damaging family relationships.

In focus groups the HTCs in the prison, said that their training had brought about a positive change in their attitudes to a healthy lifestyle. One HTC said he had "cut down on cakes and fried food" (I6) and others had tried to incorporate more healthy food into their diets.

While increased motivation for living a healthier lifestyle was seen as a benefit of their role, HTCs said that the constraints of the prison environment made achieving this difficult. "It's hard to get perishable goods . . . we still can't get fresh fruit" (I5).

HTCs in the prison reported an increase in skills and knowledge, which had changed their attitudes to learning generally. For example, one was studying for a university degree, and another was taking his HTC experience into a personal fitness role. One HTC had become a representative on prisoner committees, and several HTCs were providing mentoring to new HTCs. 
Theme B: Self-Reported Impact on Clients' Behavior. The evaluation questionnaire captured clients' self-reported reactions to the HT/HTCs interventions across the sites. Twenty-eight satisfaction questionnaires were returned from the prison, six from probation services, and nine from the mental health center.

Overall clients reported a positive experience of HT/HTC services, with 35 out of 43 clients indicating that the service was "definitely useful," and 8 rating it "mostly useful." Of the 43 clients across the sites, 36 clients said that they would return to an HT/HTC.

A change in lifestyle was most evident in clients' reported behavior in the mental health center. In the focus group, three clients said they had a healthier lifestyle and an improved social life. Clients said that they continued with activities that they enjoyed, and they felt confident to incorporate this into their daily routines outside of the center.

Cycling got me thinking about what else I can do rather than just do that ... . with exercising, it is nice to vary it so it is not just one thing and doesn't become boring and repetitive. (I6)

As far as activity and stuff, I am planning to buy a cross trainer for the benefits you get from exercise ... it's making me want to do something every day. The benefit of exercise is just brilliant. (I7)

With respect to the social benefits that came from joining in with group activities, clients said this gave them incentive to participate, to make friends, and to maintain these friendships beyond the HT/HTC service.

It's a springboard because we're friends now and we go to the cinema together, we go out for meals together. So outside of here we've been given the opportunity to make new friends and do things other than what we do here. I used to feel very isolated. (I8)

\section{DISCUSSION}

In the probation services where all three HTs were women, the role was discontinued after its trial period due to funding cuts and the difficulties in demonstrating impact. Compared with the prison and mental health center, clients in probation services reported the least impact on behavior and were difficult to track during the evaluation because of high nonattendance rates. In terms of "peer support," the HTs in probation services were "furthest removed" from their clients in terms of background and experience as the HTs had been recruited into their roles based on previous health services' experience rather than as ex-offenders. However, the finding that 5 times more female clients than males engaged with the service may reflect the fact that the HT input was provided by other women. Organizational support in the probation services was more fragmented than in the prison and mental health center as a result of recurrent changes of personnel, and the plan to introduce ex-offenders as HTCs to support the HTs did not materialize. HTs and their managers constantly complained of clients needing prior input, for example with mental health and housing issues, before they considered them to be ready for the HT service.

The HTC project within the prison was regarded as having a positive impact on clients, particularly because HTCs supported health care staff in the prison by giving clients general health information and encouraging prisoners to attend health care appointments.

The mental health center achieved high targets for client engagement with PDPs in its first year, which led to commissioners continuing to fund the service.

It is very hard to see the future now without a health trainer here, and that's just after less than a year in. (I9)

The task of comparing outcomes across the three sites was challenging due to the differences in level of client engagement and the low number of client satisfaction questionnaires returned. However, the mental health center and prison experienced the smoothest integration of HT/HTCs into their service as evidenced by the stakeholder interviews, which was attributed in part due to the more contained setting.

Evaluation at the organizational context level offers some support to the previous findings of Trayers and Lawlor (2007) that the social circumstances of the individual are important for creating behavior change. The clients from the prison were in a stable, contained environment, and the clients in the mental health center were already attending prior to the HT service being introduced. Both environments could be considered "accessible" for clients, and integration of the HT/ HTCs was well supported by managers and the coordinator, which made it easy for them to be approached directly and to remain in the consciousness of clients' minds when needing support.

The high nonattendance rates in the probation services suggests a different story, with offenders leading chaotic lifestyles and finding it difficult to attend sessions. This pattern reflects a similar finding by Dooris et al. (2013). Despite the best efforts of HTs to remind individuals 
about appointments, lack of engagement caused a real barrier to their intervention and follow-up.

Irrespective of their location, trust between HT/HTCs and their clients was the backbone that led to effective health education and promotion. HTCs in the prison were highly regarded and considered trustworthy by prison staff, which supports previous research that HT/ HTCs in prisons can be an invaluable resource (Sirdifield, 2006). Clients in the mental health center found it difficult at first to trust the HT, particularly as attempts were made to link his input with checking medication compliance. Once this was accepted as unwelcome and the HT operated a more informal client-led approach, uptake increased. This highlights the importance of giving clients with severe mental health problems a genuine choice about whether or not to engage with the HT (Bailey \& Kerlin, 2012; Crone \& Guy, 2008).

Self-reported benefits to clients and HT/HTCs extended beyond immediate health benefits. For example, in the mental health center, clients reported improvements to their social life and a reduction in their symptoms, which supports previous research that physical activity can help reduce social isolation (Richardson et al., 2005). In the prison, HTCs reported an increase in skills gained through their training and working as HTCs. This reflects other studies where offenders have gained valuable new skills and knowledge in a custodial environment (Brooker \& Sirdifield, 2007; Perrin \& Blagden, 2014). HTCs acquired new skills and used these skills to gain qualifications or new roles inside and outside of the prison supporting the need for career pathways for HTs as identified by Rahman and Wills (2013).

\section{CONCLUSIONS}

Findings in this study highlight the effective role that HTs and HTCs can play with "difficult"-to-engage groups providing that they are well supported and the services delivered in accessible settings. Across the three sites, not all HT/HTC clients contributed to the evaluation, and therefore examining the impact of the HT initiative from the client perspective is based on an "engaged" sample. Evidence arising from the probation services suggests that individuals leading chaotic lifestyles are harder to engage by HTs. Clients' ambivalence about the HTs' role was attributed to clients reporting more significant needs relating to mental illness and homelessness, which rendered the HT service less relevant.

Based on this study and similar evaluations (White et al., 2013), there is a need for longitudinal research in the United Kingdom to follow-up and track the longer term benefits of HT/HTC services with clients followed up in a range of settings to establish whether behavior change as a result of HT/HTC intervention is sustained and how social and political factors might contribute to this.

\section{REFERENCES}

Bailey, D. (2002). Training together-part two: An exploration of the evaluation of a shared learning programme on dual diagnosis for specialist drugs workers and ASWs. Social Work Education, 21, 685-699.

Bailey, D. (2007). Evaluating training for collaborative practice for graduate primary care mental health workers: Part 2. Journal of Mental Health Training, Education and Practice, 2, 19-29.

Bailey, D., \& Kerlin, L. (2012). What is the impact of health trainer interventions within a mental health setting? International Journal of Mental Health Promotion, 14, 139-150.

Bailey, D., \& Littlechild, R. (2001). Devising the evaluation strategy for a mental health training programme Evaluation, 7, 351-368.

Barr, H., Freeth, D., Hammick, M., Koppel, I., \& Reeves, S. (2000). Evaluating interprofessional education: A United Kingdom review for health and social care. London, England: BERA/CAIPE.

Baybutt, M., \& Dooris, M. (2011). Evaluation of Rochdale offender health trainers' demonstration project: Report of findings (NHS, North West Health Trainer Partnership). Retrieved from https:// www.uclan.ac.uk/research/explore/projects/assets/rochdale_probation_oht_evaluation_report.pdf

Brooker, C., \& Sirdifield, C. (2007). New futures health trainers: An impact assessment. Lincoln, England: Centre for Clinical and Academic Workforce Innovation.

Crone, D., \& Guy, H. (2008). "I know it is only exercise, but to me it is something that keeps me going": A qualitative approach to understanding mental health service users' experiences of sports therapy. International Journal of Mental Health Nursing, 17, 197-207.

Data Collection Reporting System. (2010). Health trainers DRCS (National HUB Report). Retrieved from http://healthtrainersengland.com/wp-content/uploads/2014/05/National_Health_Trainer_ DCRSv11_201012071.pdf

Denness, H., Keeton, R., \& Fearn, T. (2011). Evaluation of the Derbyshire health trainer programme. Derbyshire, England: NHS.

Department of Health. (2004). Public health white paper: Choosing health: Making healthy choices easier. London, England: Author.

Department of Health. (2010). Healthy lives: Healthy people (White paper). London, England: Author.

Dooris, M., McArt, D., Hurley, M. A., \& Baybutt, M. (2013). Probation as a setting for building well-being through integrated service provision: Evaluating an offender health trainer service. Perspectives in Public Health, 133, 199-206.

DuBrin, A. J. (2013). Principles of leadership. Independence, KY: South-Western Cengage Learning.

Humphrey, A. (2005, December). SWOT analysis for management consulting. SRI Alumni Newsletter. Retrieved from http://www. sri.com/sites/default/files/brochures/dec-05.pdf 
Kirkpatrick, D. L. (1994). Evaluating training programs: The four levels. San Francisco, CA: Berrett-Koehler.

Mason, L., Knuckey, S., Perkins, C., \& Bellis, M. (2011). Health trainers in the North West: A report commissioned by the North West health trainer partnership (NHS, North West Public Health Observatory). Retrieved from http://www.nwph.net/nwpho/ Publications/healthtrainers.pdf

Michie, S., Rumsey, N., Fussell, A., Hardeman, W., Jonston, M., Newman, S., \& Yardley, L. (2008). Improving health: Changing behaviour: NHS health trainer handbook. London, England: Department of Health.

Morgan, A. (2011). Service evaluation of health trainers in NHS Nottinghamshire and NHS Bassetlaw. Journal of Health and Social Care Improvement, February, 1-9.

Perrin, C., \& Blagden, N. (2014). Accumulating meaning, purpose and opportunities to change "drip by drip": The impact of being a listener in prison. Psychology, Crime \& Law, 20, 902-920.

Preston, I., \& Romero, I. (2011). Gloucestershire community health trainer service: Annual report 2010-2011. Gloucestershire, England: NHS.

Rahman, E., \& Wills, J. (2013). The career journeys of health trainers in two health trainer services in England. Perspectives in Public Health, 133, 207-212.

Richardson, C. R., Faulkner, G., McDevitt, J., Skrinar, G. S., Hutchinson, D. S., \& Piette, J. D. (2005). Integrating physical activity into mental health services for persons with serious mental illness. Psychiatric Services, 56, 324-331.

Sirdifield, C. (2006). Piloting a new role in mental health-prison based health trainers. Journal of Mental Health Workforce Development, 1, 15-22.
South, J., Woodward, J., \& Lowcock, D. (2007a). An evaluation of the Bradford district health trainers' programme: An early adopter site. Leeds, England: Centre for Health Promotion Research, Leeds Metropolitan University.

South, J., Woodward, J., \& Lowcock, D. (2007b). New beginnings: Stakeholder perspectives on the role of health trainers. Journal of the Royal Society for the Promotion of Health, 127, 224-230.

Stake, R. E (1995). The art of case study research. Thousand Oaks, CA: Sage.

Strauss, A., \& Corbin, J. M. (1998). Basics of qualitative research techniques and procedures for developing grounded theory. Thousand Oaks, CA: Sage.

Trayers, T., \& Lawlor, D. A. (2007). Bridging the gap in health inequalities with the help of health trainers: A realistic task in hostile environments? A short report for debate. Journal of Public Health, 29, 218-221.

Triangle Consulting Social Enterprise. (2009). Outcomes Star ${ }^{\mathrm{TM}}$. Retrieved from http://www.outcomesstar.org.uk/

Warr, P., Bird, M., \& Rackham, N. (1970). Evaluation of management training. London, England: Gower Press.

White, J., \& Kinsella, K. (2011). Scarborough health trainer service: Evaluation report for the period January to October 2010. Leeds, England: Centre for Health Promotion Research, Leeds Metropolitan University.

White, J., Woodward, J., \& South, J. (2013). Addressing inequalities in health: What is the contribution of health trainers? Perspectives in Public Health, 133, 213-220.

Yin, R. K. (2009). Applied social research methods series: Vol. 5. Case study research: Design and methods (4th ed.). Thousand Oaks, CA: Sage. 